\title{
Comparison among fertility-sparing therapies for well differentiated early-stage endometrial carcinoma and complex atypical hyperplasia
}

\author{
Qing Zhang ${ }^{1,2, *}$, Gonghua $\mathbf{Q i}^{1,4, *}$, Margaux J. Kanis ${ }^{3}$, Ruifen Dong ${ }^{1}$, Baoxia Cui ${ }^{1}$, \\ Xingsheng Yang ${ }^{1}$ and Beihua Kong ${ }^{1,2}$ \\ ${ }^{1}$ Department of Obstetrics and Gynecology, Qilu Hospital, Shandong University, Ji'nan, Shandong, 250012, P.R. China \\ ${ }^{2}$ Gynecology Oncology Key Laboratory, Qilu Hospital, Shandong University, Ji'nan, Shandong, 250012, P.R. China \\ ${ }^{3}$ Division of Gynecologic Oncology, Department of Obstetrics and Gynecology, Northwestern University Feinberg School of \\ Medicine, Chicago, IL, 60611, USA \\ ${ }^{4}$ School of Medicine, Shandong University, Ji'nan, Shandong, 250012, P.R. China \\ *These authors contributed equally to this work
}

Correspondence to: Beihua Kong, email: kongbeihua@sdu.edu.cn

Keywords: endometrial carcinoma, complex atypical hyperplasia, fertility-sparing therapy, hysteroscopic resection, oral progestogens Received: December 15, 2016

Accepted: April 05, 2017

Published: May 03, 2017

Copyright: Zhang et al. This is an open-access article distributed under the terms of the Creative Commons Attribution License 3.0 (CC BY 3.0), which permits unrestricted use, distribution, and reproduction in any medium, provided the original author and source are credited.

\section{ABSTRACT}

Objective: To compare fertility-sparing therapies including oral progestogens, hysteroscopic resection (HR), and the levonorgestrel- releasing intrauterine system (LNG-IUS) in achieving disease regression, recurrence and live birth rate in well differentiate early-stage endometrial carcinoma (eEC) and complex atypical hyperplasia(CAH).

Study Design: This was a meta-analysis of previous studies focus on the fertilitysparing therapy for well differentiate early-stage endometrial carcinoma (eEC) and complex atypical hyperplasia (CAH).

Date Sources: Medline, the Cochrane Library and Embase was searched with the terms and Synonyms: words similar to eEC and CAH with therapies associated with fertility-sparing.

Main Outcome Measures: The number of all patients accepted fertility sparing therapies, patients got regressed, relapsed and delivered were extracted from each study, and the regression, recurrence, and live birth rate of each study were calculated. The regression, recurrence and live birth rates between each two interventions were compared with the aid of meta-regression in packages of "meta" and "meta for" written in $\mathbf{R}$.

Results: Fifty-four studies reported fertility sparing therapies in young women with eEC and CAH were included. Meta-analysis showed that HR followed by progestogens achieved a higher pooled regression $(98.06 \%$ vs $77.20 \% P<0.0001)$ and live birth rate $(52.57 \%$ vs $33.38 \%, P=0.0944)$ and a lower recurrence rate compared with oral progestogens alone $(4.79 \%$ vs $32.17 \% P=0.0004)$. At the same time, the pooled live birth rate $(52.57 \%$ vs $18.09 \% P=0.0399)$ of HR followed by progestogens are significantly higher than the LNG-IUS alone. Which no statistical difference in regression $(98.06 \%$ vs $94.24 \% ; P=0.4098)$ and recurrence rates (4.79\% vs $3.90 \% P=0.8561)$ was seen.

Conclusions: Of the available fertility-sparing therapeutic options, HR followed by progestogens may be a more effective one. 


\section{INTRODUCTION}

Endometrial carcinoma (EC), the most common malignancy of the female genital tract, and complex atypical hyperplasia (CAH), its precursor lesion, most frequently affects peri- and post-menopausal women. It is reported that the incidence of EC among women 40 years or younger comprised $14.4 \%$ of all patients diagnosed with EC between 1976-1983 [1]. However, the incidence of young women who are diagnosed with $\mathrm{EC}$ and $\mathrm{CAH}$ is increasing, particularly as the rate of obesity increases and popularity of postpone delivery age. This poses a dilemma for those who wish to retain fertility as a total hysterectomy and bilateral salpingo-oophorectomy (TH/BSO) is the standard treatment. Recent studies have focused on fertility-sparing therapy for early-stage endometrial carcinoma (eEC) and CAH. Oral progestogens such as megestrol acetate (MA) and medroxyprogesterone acetate (MPA) were most frequently used [2], but in recent years, the levonorgestrel-releasing intrauterine system (LNG-IUS) [3], and hysteroscopic resection(HR) of the cancer or hyperplastic area followed by oral or intrauterine progestogens have been demonstrated to be safe and effective alternatives [4, 5]. However, previous reports of these are limited to small sample studies and meta-analysis [6,7], and few focus on the comparison among these therapies $[8,9]$. In this report, we systematically review previously published observational studies, relative reviews and meta-analyses to perform a meta-analysis in comparing among their treatment effects.

\section{RESULTS}

The electronic search identified 2047 citations in Medline, the Cochrane Library and Embase. Of these, 1919 were excluded as the title and abstracts not meet the inclusion criteria. One hundred and twenty-eight publications were obtained, and another 74 were excluded for not meeting the inclusion criteria after thorough reading of the paper. In the final analysis, 54 articles $[6,10-62]$ were included. The process of article selection can be seen in Figure 1. Detailed information of the included studies and quality analysis are presented in See Supplementary Table 4 and Figure 2.

\section{Hysteroscopic resection with or without progestogens compare to oral progestogens alone}

Meta-analysis of the studies focusing on women with eEC and CAH treated with hysteroscopic resection(HR) with or without another methods such as progestogens or GnRH agonist showed a pooled regression, recurrence and live birth rate of $98.06 \%$ (95\% [CI], 90.32-100.00), 4.79\% (95\% [CI], 0.16-15.23), and 52.57\% (95\% [CI], 24.66$79.64)$, respectively. Studies focusing on oral progestogens alone found a pooled regression, recurrence and live birth rate of $77.20 \%$ (95\% [CI], 72.58-81.51), 32.17\%
(95\% [CI], 25.06-39.71), and 33.38\% (95\% [CI], 26.70-40.42), respectively. Meta-analysis showed that HR with or without progestogens achieved a statistical significantly higher pooled regression rate $(P<0.0001)$ (See Figure 3 ), and a slightly higher live birth rate $(P=0.0944)$ though without statistical sense (See Figure 4) and a statistically significant lower recurrence rate $(P=0.0004)$ (See Figure 5) compared with oral progestogens alone (See Table 1).

\section{Hysteroscopic resection with or without progestogens and LNG- IUS alone}

Meta-analysis of those with eEC and CAH treated with LNG-IUS have a pooled regression, recurrence and live birth rate of 94.24\% (95\% [CI], 83.23-99.60), $3.90 \%$ (95\% [CI], 0.08-12.98) and 18.09\% (95\% [CI], 7.42-32.14), respectively. The pooled live birth rate $(P=0.0399)$ (See Supplementary Figure 1) for eEC and $\mathrm{CAH}$ after HR are significantly higher than LNG-IUS alone. There was no statistical difference in the regression $(P=0.4098)$ (See Supplementary Figure 2) and recurrence $(P=0.8561)$ (See Supplementary Figure 3$)$ rate between these two methods (See Supplementary Table 1).

\section{Oral progestogens alone for $\mathrm{EEC}$ and $\mathrm{CAH}$}

Women with eEC treated with oral progestogens alone had a pooled regression, recurrence and live birth rate of $79.47 \%(95 \%$ [CI], 73.19-85.10), 27.34\% (95\% [CI], 18.19-37.56) and 32.28\% (95\% [CI], 22.87-42.48), respectively. A pooled regression, recurrence and live birth rate of $88.74 \%(95 \%$ [CI], 81.70-94.25), 9.20\% (95\% [CI], 3.91-16.43) and 28.74\% (95\% [CI], 19.20-39.35), respectively, was achieved in patients with $\mathrm{CAH}$ who were treated with oral progestogens only. Compared to those with eEC, women with $\mathrm{CAH}$ achieved a statistically significant higher regression $(P=0.0417)$ and a relatively lower recurrence rate $(P=0.0044)$ but no difference in live birth rates $(P=0.7247)$ when treated with oral progestogens (See Supplementary Table 2).

\section{DISCUSSION}

The efficacy and safety of oral progestogens as fertility-sparing therapy in patients with eEC and $\mathrm{CAH}$ has been reported in many small studies, the first report was in 1961 by Kelley and Baker [63]. It functions by inhibition of the estrogen receptor, leading to a decrease in endometrial cell mitosis, promotion of apoptosis, and production of secretory endometrium.

The overall complete response rate for both eEC and CAH ranges from 62.5 to $89 \%[17,48,52,53,64]$. In 2010, Serkanli and Ayhan [65] reviewed 231 cases and the overall response rate was $75.3 \%(n=174)$, and another recent meta-analysis showed a response rate of $72 \%(95 \%$ 


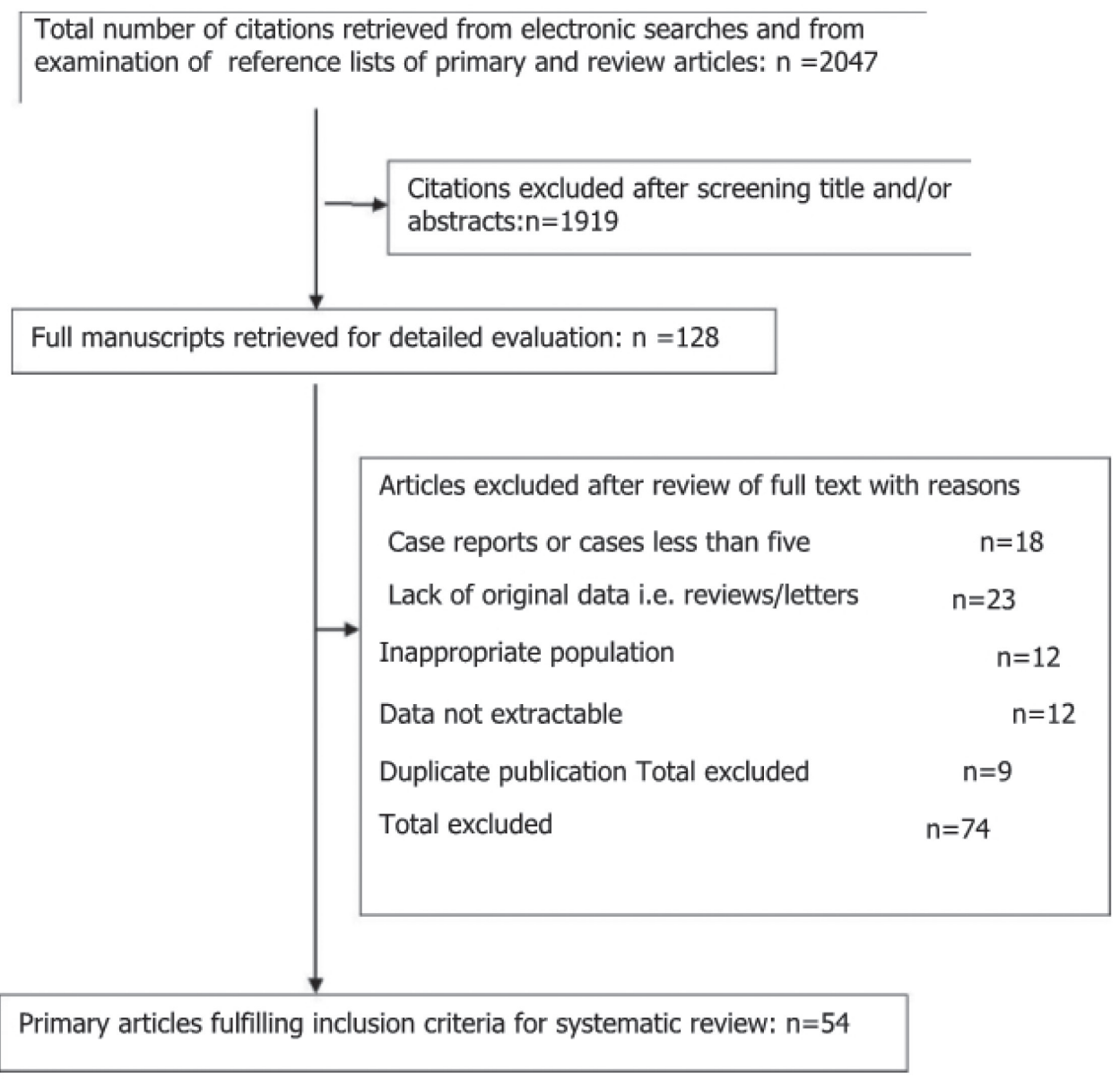

Figure 1: Study selection process.

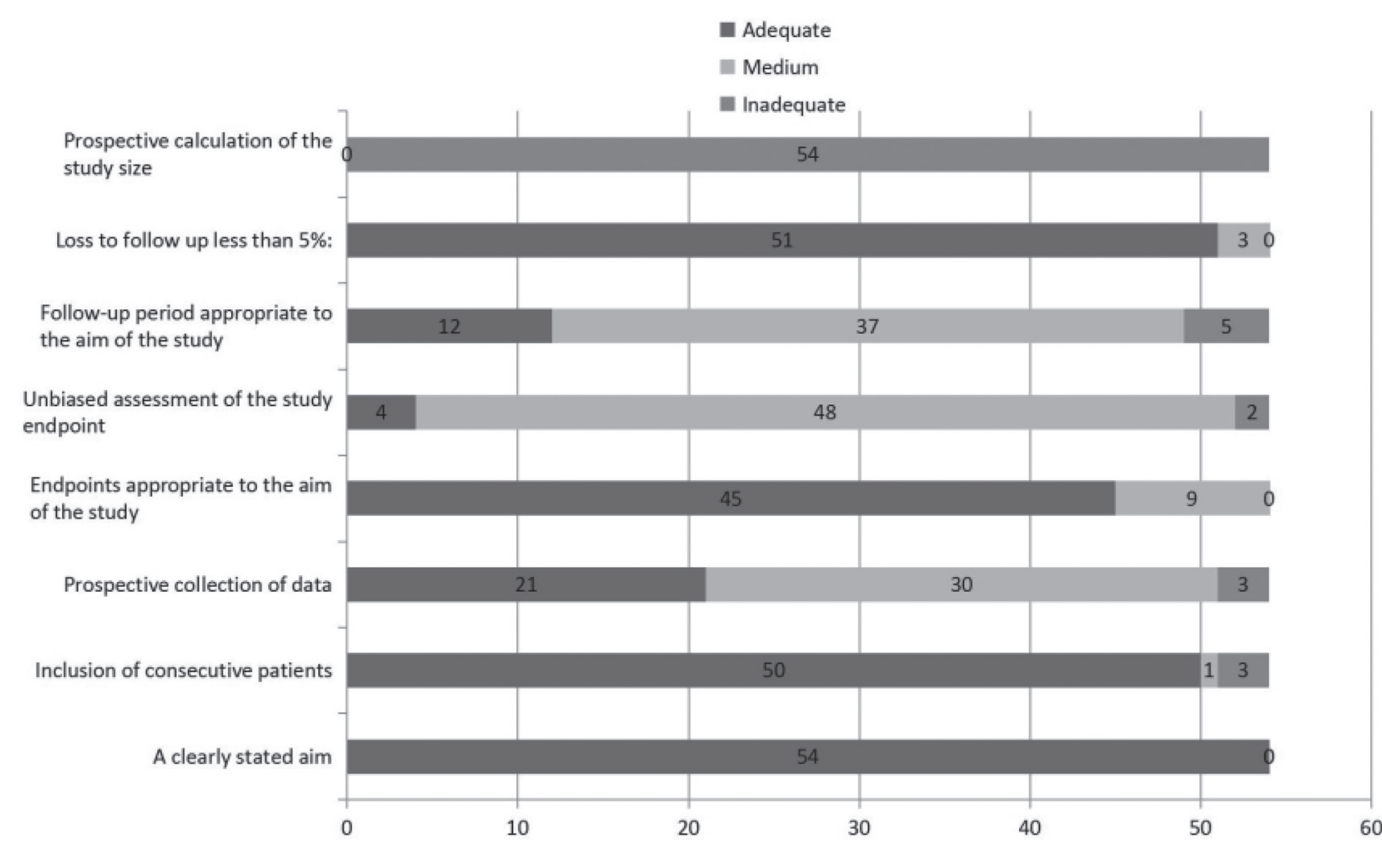

Figure 2: Quality assessment of the studies. 
CI $62-80 \%$ ) [66]. It is reported that the regression rate for eEC and $\mathrm{CAH}$ is $57 \%-75 \%$ and $83 \%-94 \%$, respectively $[1,22]$. A pooled regression rate of $76.2 \%$ for $\mathrm{eEC}$ and $85.6 \%$ for CAH was reported in a meta-analysis made by Gallos et al. [8]. In our study, we report a total pooled regression rate of $88.74 \%$ for $\mathrm{CAH}$ and $79.47 \%$ for $\mathrm{eEC}$, which is similar to previously published studies and found that the success rate is lower in women with eEC than those with CAH, the same as reported in Hara' article [23].

The recurrence rates for eEC and $\mathrm{CAH}$ in Gallos' meta-analysis was $40.6 \%$ and $26 \%$, respectively [8]. A lower total pooled relapse rate of $27.34 \%$ for eEC and $9.20 \%$ for CAH was obtained from our meta-analysis. Reasons may be that we only exact the G1 EC other than all grades in their report, which affects the recurrence rate of the disease. While successful regression is important, the live birth rate is crucial to justifying the efficacy of fertility-sparing therapies. We found a pooled live birth rate of $33.38 \%$, comparable to the rate of $28 \%$ in Gallos et al. meta-analysis [8].

The LNG-IUS acts on the progesterone receptors in the endometrium directly, thus the concentration of progesterone has been found to be much higher in the endometrial mucosa [67]. Studies focusing on the efficacy and safety of the LNG-IUS are also insufficient, and many use it only in conjunction with oral progestogens, although several recent studies have shown satisfying results [5, 29, 67-69]. Furthermore, some studies suggest that the LNG-IUS is superior to oral progestogens, Gallos et al. [5] reported a systematic review that LNG-IUS achieved

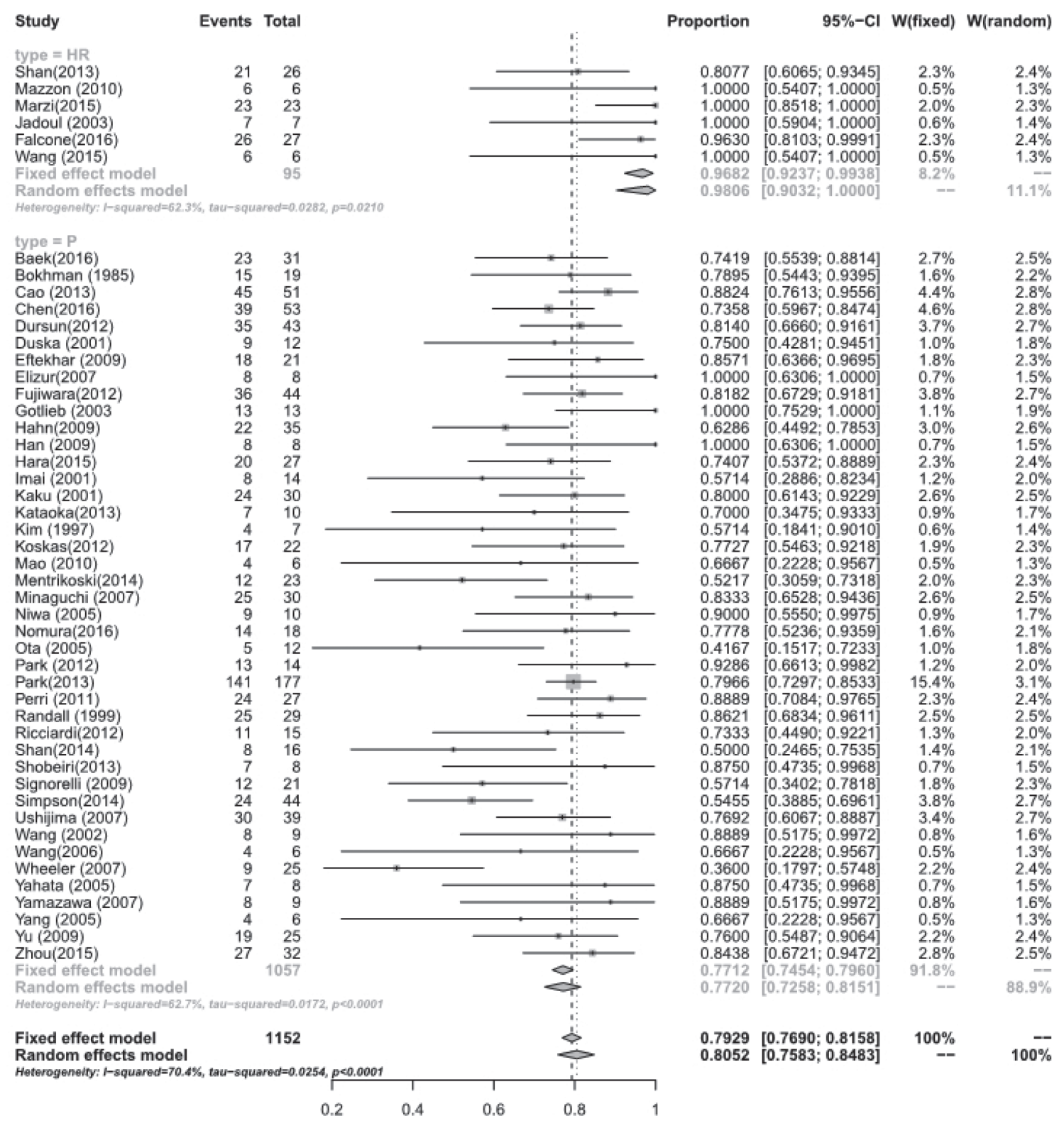

Figure 3: Regression rate between hysterscopic resection (HR) and oral progestogens (P). 
a higher pooled regression rate than oral progestogens for CAH (90 vs 69\%, $P=0.03$ ). A higher regression rate (53/53, 95\% CI 0.93-1.0) was also seen in a randomized, multicenter study carried out by Orbo et al. [67]. Similar result also reached in our study, a higher pooled regression rate of $94.24 \%$ vs $77.20 \%(P=0.0010)$ for LNG-IUS compared to oral progestogens. This is similar to a study by Kim et al. [29] in which an 87.5\% (14/16) complete response rate was obtained. However Baker et al. [10] found that treatment with oral or intrauterine progestogens is similarly effective, similar conclusion is reported in several studies $[5,32]$.

The recurrence rate of LNG-IUS in our study is $3.90 \%$, which is significantly lower than oral progestogens alone $(P=0.0001)$. The live birth rate is $18.09 \%$ without significant difference with oral progestogens $(P=0.1242)$ (See Supplementary Table 3 ) suggesting LNG-IUS may still be a useful treatment option, especially since it has less systemic side-effects such as weight gain and irregular vaginal bleeding [70].

Hysteroscopic resection (HR) as a fertility-sparing treatment for eEC and CAH is less frequently used. Most articles report on HR followed by oral progestogens or GnRH agonists. A recent updated meta-analysis reported the regression rates of hormones only, surgery only, and hormones and surgery combined as $49.6 \%$ (111/224), 75\% $(3 / 4)$, and $100 \%(3 / 3)$, respectively [65]. The superiority of the combination is evident. A similar regression rate to our $97.25 \%$ can be seen with other published studies $[6,32,71]$. In comparison with oral progestogens, a

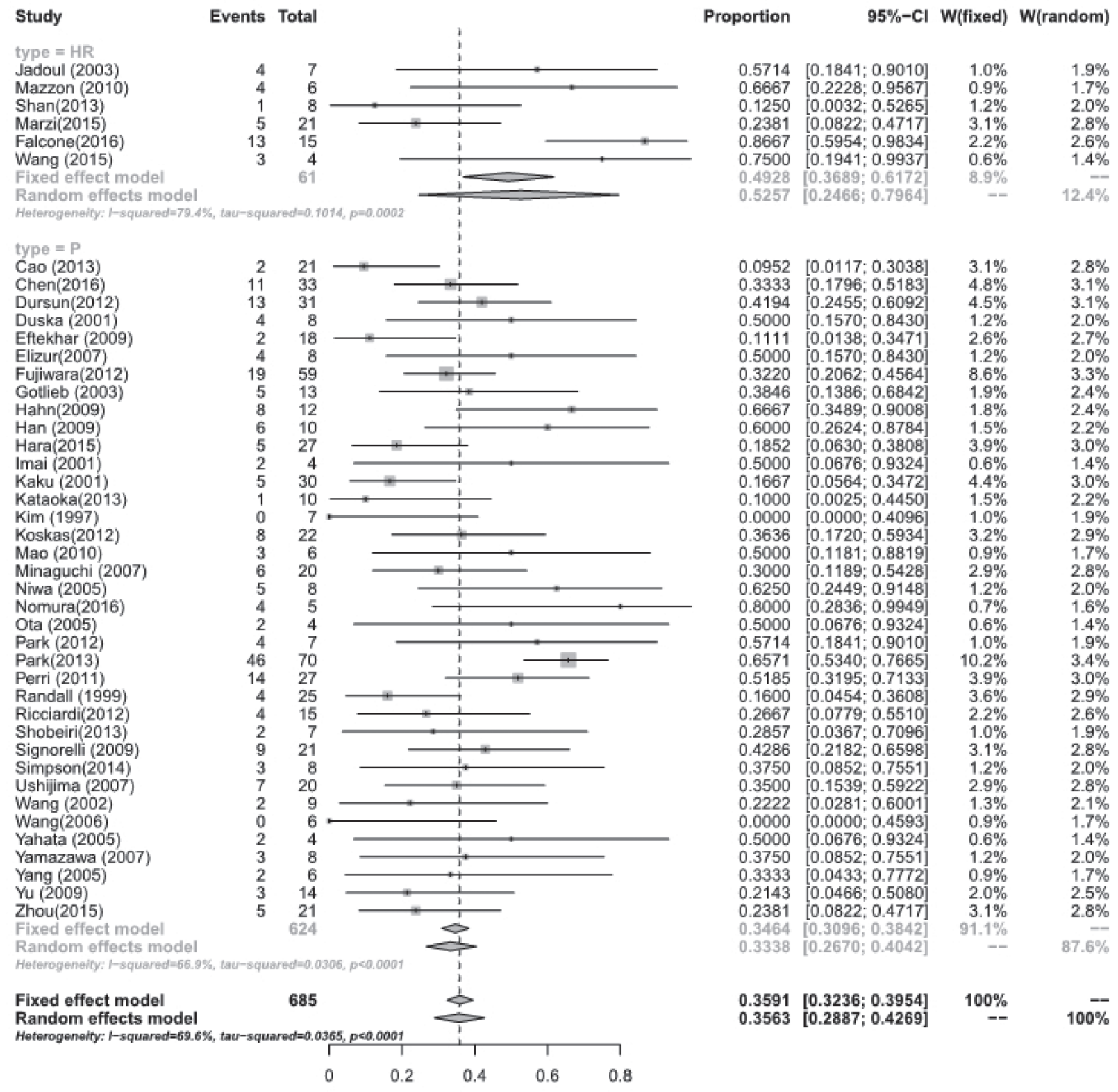

Figure 4: Live birth rate between hysterscopic resection (HR) and oral progestogens (P). 
statistically significant higher response rate $(98.06 \%$ vs $77.20 \%$ ) was achieved in our study. Our recurrence rate was $4.79 \%$, similar to the $7 \%$ rate in Laurelli's study [71], but lower than $30 \%$ for CAH and $27.3 \%$ for EC in Shan et al. [46]. The live birth rate reported in previous studies varies from $25 \%$ to $66.6 \%[6,46]$, similar to our finding $52.57 \%$. The potential superiority of the HR followed by hormonal therapy compared with oral progestogen use alone is evident.

HR consisted of three steps: excluding the lesion areas, the nearly endometrium and the myometrium under the lesion $[6,32,71]$. This operation could lead to accuracy diagnosis of the pathology and myometrial invasion. HR also helps improve the efficacy of progestogen due to less tumor burden. As a result, a higher regression rate and a shorter time between diagnosis and regression [72]. Some complication of HR such as endometrial destruction, intrauterine adhesion, which can affect the reproductive outcomes of young patients desire to preserve their fertility as mentioned before [73]. It is reported that in the study of Marzi et al. [32], a study aimed to evaluate the rate of intrauterine adhesions of HR as fertility-sparing therapy and found no intrauterine adhesions at the follow-up diagnostic hysteroscopy even in patients accepted more than once HR. Meanwhile, diagnostic hysteroscopy can found the uterine synechia caused by serial dilation and curettage (D\&C) at followup and operate hysteroscopic adhesiolysis [22]. A

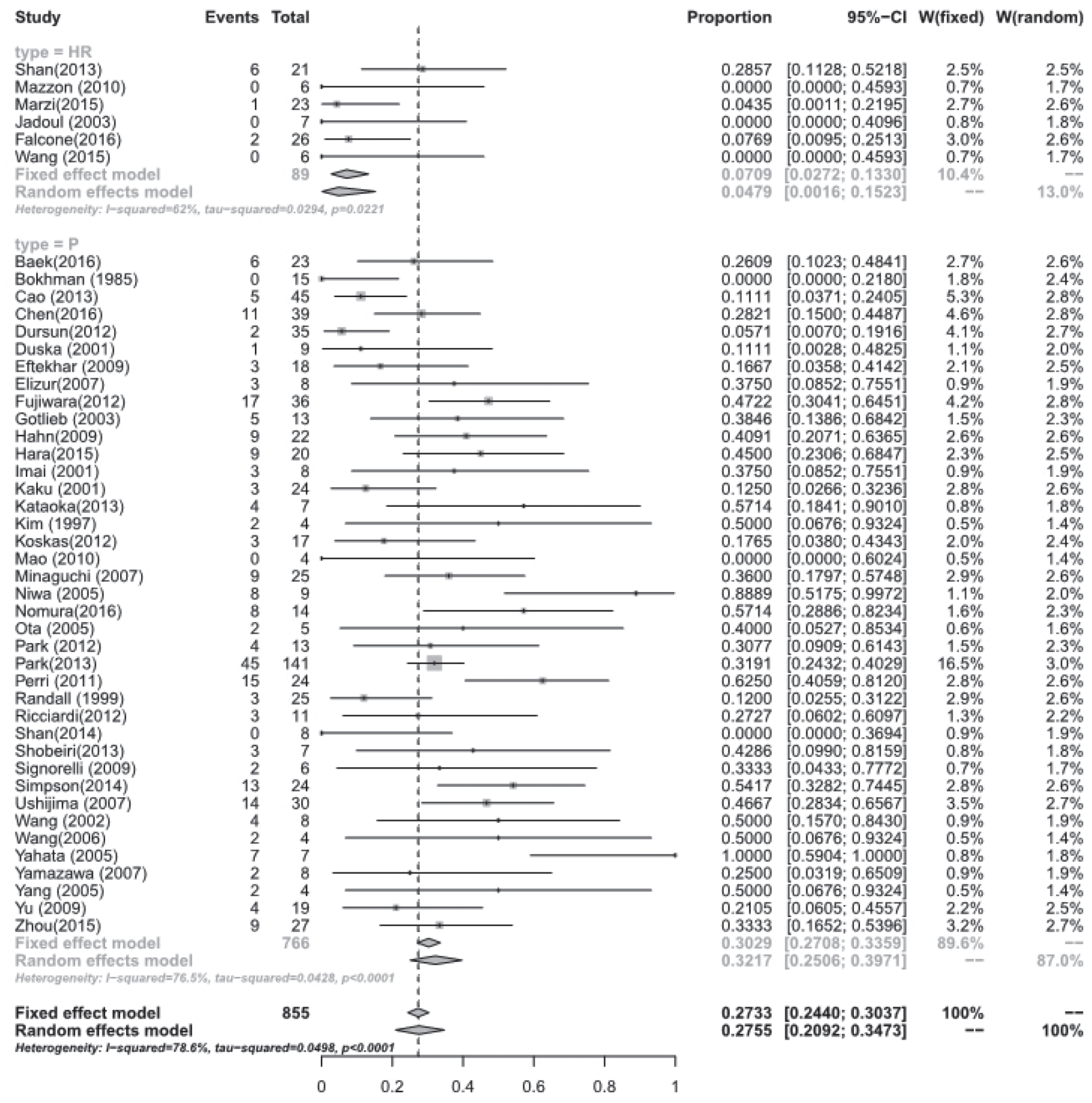

Figure 5: Recurrence rate between hysterscopic resection (HR) and oral progestogens (P). 
Table 1: Regression, recurrence and live birth rate of hysteroscopic resection (HR) and oral progestogens (p)

\begin{tabular}{|c|c|c|c|c|c|c|}
\hline & Number of studies & Test for Heterogeneity $\left(I^{2}\right)$ & Test for Heterogeneity: (tau-squared) & Fixed effect model (effect size, $95 \%$ CI) & $\begin{array}{l}\text { Random effects model } \\
\text { (effect size, } 95 \% \mathrm{CI} \text { ) }\end{array}$ & $P$ value \\
\hline Regression rate & & & & & & $<0.0001$ \\
\hline In HR & 6 & $62.3 \%$ & 0.0210 & $0.9682[0.9237 ; 0.9938]$ & $0.9806[0.9032 ; 1.0000]$ & \\
\hline In $\mathrm{P}$ & 45 & $62.7 \%$ & $<0.0001$ & $0.7712[0.7454 ; 0.7960]$ & $0.7720[0.7258 ; 0.8151]$ & \\
\hline Recurrence rate & & & & & & 0.0004 \\
\hline In HR & 6 & $62 \%$ & 0.0221 & $0.0709[0.0272 ; 0.1330]$ & $0.0479[0.0016 ; 0.1523]$ & \\
\hline In $\mathrm{P}$ & 39 & $76.5 \%$ & $<0.0001$ & $0.3029[0.2708 ; 0.3359]$ & $0.3217[0.2506 ; 0.3971]$ & \\
\hline Live birth rate & & & & & & 0.0944 \\
\hline In HR & 6 & $79.4 \%$ & 0.0002 & $0.4928[0.3689 ; 0.6172]$ & $0.5257[0.2466 ; 0.7964]$ & \\
\hline In $\mathrm{P}$ & 37 & $66.9 \%$ & $<0.0001$ & $0.3464[0.3096 ; 0.3842]$ & $0.3338[0.2670 ; 0.4042]$ & \\
\hline
\end{tabular}

recent prospective study focused on HR and progestin therapy reached a live birth rate of $50 \%$ in all treated patients and $86.6 \%$ for women who tried to conceive with no complications [72]. Another problem may be the dissemination of cancerous cells into the peritoneal cavity during hysteroscopy, it is reported that it didn't risk recurrence rate and the long-term prognosis is unclear $[16,74,75]$. Far from satisfactory, the low fertility rates can be explained by the fact that many women diagnosed with eEC or CAH are overweight, obese, anovulation or have polycystic ovarian syndrome all of which significantly impact the pregnancy rate $[1,22,24,76]$. It is reported that a higher pregnancy and live birth rate in use of Assisted Reproductive Technology(ART) than spontaneous conception in young women with EC [14, 40, 72]. Patients who reached regression with fertility sparing therapy, immediately conceive should be suggested especially under ART.

The standard therapy for women with eEC and $\mathrm{CAH}$ still $\mathrm{TH}$ and BSO, so definite surgery is strongly suggested once a persisted or progression disease was found or after finishing delivery. We extracted the patients who undergone definite surgery and the final pathology. A total of 381 patients accepted standard therapy of which 37 patients $(9.7 \%)$ showed no residual lesion, while persistent disease was seen in 219 women (57.5\%). Unfortunately, ninety patients $(23.6 \%)$ were diagnosed with progression when $\mathrm{TH}$ and BSO was operated and 6.5\% (25) women with concurrent ovarian cancer. A recent study aimed at the EC developing risk between young women with $\mathrm{CAH}$ accepted fertility-sparing therapy and primary hysterectomy, finding that fertility-sparing therapy delays the occurrence of EC without increasing its risk [73]. The incidence of concurrent ovarian cancer was 5\% as reported [77], a similar rate in our study. To exclude ovarian cancer before fertility sparing therapy, serum CA125 and diagnostic laparoscopy was used $[62,72,78]$. About $5 \%$ to $10 \%$ young patients with EC may be a candidate for Lynch syndrome $[15,16,61,72]$, so that it is essential to evaluate it before conservative treatment. According to our search, only seven studies performed.

The limitations of this study take into account the publications on which they were based. Publication bias exists due to possible overestimation of reported success rates. Insufficient studies on HR and LNG-IUS is another defect. Many of these reports are retrospective and include small sample sizes with limited follow up. Although fertility-sparing therapy does appear to be effective for women with eEC and $\mathrm{CAH}$, with satisfactory regression and live birth rates, the recurrence rate is still concerning. Close, long-term surveillance should be performed.

In conclusion, hysteroscopic resection followed by progestin as fertility-sparing therapy may be a more effective option for women with CAH or EC. Further studies are needed to evaluate HR with or without hormonal therapy or a LNG_IUS, as well as the combination of LNG-IUS and oral .

\section{MATERIALS AND METHODS}

\section{Identification of literature}

The population of interest is young women aged 44 years or younger with early stage (International Federation of Gynecology and Obstetrics stage I) Grade 1 EC or CAH, who underwent fertility-sparing therapy including MA and MPA, the LNG-IUS, and hysteroscopic resection(HR) followed by progestogens. The outcome of interest was incidence of disease regression, recurrence and live birth . We searched Medline, the Cochrane Library and Embase (from January 1950 to December 2016) with the following Medical Subject Headings (MeSH) and text words: i) Words with sense of EC: "cancer" or "carcinoma" or "adenocarcinoma" or "malignant" or "neoplasm" AND "endometrial" or "endometrium" or "corpus uteri". ii) Words with a similar meaning to CAH: "precancer" or "precursor" or "premalignant" or "precancerous" or "atypical hyperplasia" AND "endometrial" or "endometrium" or "corpus uteri". iii) Therapies associated with fertility-sparing treatment: "fertility sparing" or "fertility preserve" or "fertility preserving" or "fertility preservation" or "conservative" or "hysteroscopic resection" or "GnRH analogue" or "hormone therapy" or "progesterone" or "progestin" or "levonorgestrel-releasing intrauterine system". The following words were used to generate a subset of citations "humans and female" "age between 19-44 years old" and "language in Chinese and English".

\section{Study selection and data extraction}

Inclusion criteria were defined as: 1) Women between 19 and 44 years old;2) patients who desire 
fertility; 3) diagnosis of stage I grade I EC or CAH ; 4) treatment with fertility-sparing therapy and 5) articles written in English and Chinese. Exclusion criteria consisted of: 1) Women aged 45 or older; 2) those who underwent conservative treatment due to high perioperative risks; 3 ) patients with greater than stage IA disease(invading deep myometrium or distant metastasis) or pathology other than endometrioid adenocarcinoma; 4) patients with simple hyperplasia or complex hyperplasia without atypia; 5) case reports and small studies with fewer than five patients; 6) articles written in languages other than English and Chinese; 7) data was unable to be extracted.

Studies were selected in two stages. Firstly, the titles and abstracts of the articles searched from Medline, the Cochrane Library and Embase were independently assessed by two reviewers. Secondly, full articles meeting the inclusion criteria according to the first step were obtained and evaluated. Any disagreements about inclusions were arbitrated by a third reviewer. Two reviewers performed the quality assessment and adhered to the Methodological Index for Non- Randomized Studies (MINORS), a widely accepted tool used to assess the quality of the included studies [79].

Disease regression was defined as eEC or $\mathrm{CAH}$ returned to normal endometrium or hyplasia without atypical during follow-up. Disease recurrence was defined as eEC or $\mathrm{CAH}$ reoccurred during follow-up in patients initially showed disease regression. Live births was the birth of healthy infants during the follow-up period, and its rate was calculated as the number of women who gave birth of healthy infants divided by the number of women accepted fertility-sparing therapy and wanted to pregnant immediately. We defined appropriate follow-up time to be at least 5 years.

\section{Statistical analysis}

After data extraction, regression, recurrence and live birth rates were calculated separately. Both a fixed and random effects model was used to obtain pooled rates [80]. Heterogeneity of the effects was statistically analyzed using the $Q$ test and $I^{2}$ test [81]. The forest plots were used to demonstrate the meta-analysis directly [81]. The regression, recurrence and live birth rates between the two interventions (HR followed by progestogens and oral progestogens, HR followed by progestogens and LNGIUS; oral progestogens and LNG-IUS) were compared with the aid of meta-regression. Packages of "meta" and "meta for" written in R were used for calculations [82].

\section{ACKNOWLEDGMENTS}

We have no Acknowledgements.

\section{CONFLICTS OF INTEREST}

The authors report no conflicts of interest.

\section{GRANT SUPPORT}

This work was supported by the National Clinical Research Center for Gynecological Oncology (2015BAI13B05), National Natural Science Foundation of China (81502251), Science and Technology Development Project of Shandong Province (2016GSF201164), National Natural Science Foundation of Shandong Province (BS2014SW009).

\section{REFERENCES}

1. Gallup DG, Stock RJ. Adenocarcinoma of the endometrium in women 40 years of age or younger. Obstetrics and gynecology. 1984; 64:417-420.

2. Benshushan A. Endometrial adenocarcinoma in young patients: evaluation and fertility-preserving treatment. European journal of obstetrics, gynecology, and reproductive biology. 2004; 117:132-137.

3. Park JY, Kim DY, Kim TJ, Kim JW, Kim JH, Kim YM, Kim YT, Bae DS, Nam JH. Hormonal therapy for women with stage IA endometrial cancer of all grades. Obstetrics \& gynecology science. 2013; 122:7-14.

4. Mazzon I, Corrado G, Morricone D, Scambia G. Reproductive preservation for treatment of stage IA endometrial cancer in a young woman: hysteroscopic resection. International journal of gynecological cancer. 2005; 15:974-978.

5. Gallos ID, Shehmar M, Thangaratinam S, Papapostolou TK, Coomarasamy A, Gupta JK. Oral progestogens vs levonorgestrel-releasing intrauterine system for endometrial hyperplasia: a systematic review and metaanalysis. American journal of obstetrics and gynecology. 2010; 203:547.e541-547.e510.

6. Mazzon I, Corrado G, Masciullo V, Morricone D, Ferrandina G, Scambia G. Conservative surgical management of stage IA endometrial carcinoma for fertility preservation. Fertility and sterility. 2010; 93:1286-1289.

7. Koskas M, Uzan J, Luton D, Rouzier R, Daraï E. Prognostic factors of oncologic and reproductive outcomes in fertilitysparing management of endometrial atypical hyperplasia and adenocarcinoma systematic review and meta-analysis. Fertility and sterility. 2014; 101:785-794.

8. Gallos ID, Yap J, Rajkhowa M, Luesley DM, Coomarasamy A, Gupta JK. Regression, relapse, and live birth rates with fertility-sparing therapy for endometrial cancer and atypical complex endometrial hyperplasia: a systematic review and metaanalysis. American journal of obstetrics and gynecology. 2012; 207:266 e261-212.

9. Abu Hashim H, Ghayaty E, El Rakhawy M. Levonorgestrelreleasing intrauterine system vs oral progestins for nonatypical endometrial hyperplasia: a systematic review and metaanalysis of randomized trials. American journal of obstetrics and gynecology. 2015; 213:469-478. 
10. Baek JS, Lee WH, Kang WD, Kim SM. Fertility-preserving treatment in complex atypical hyperplasia and early endometrial cancer in young women with oral progestin: Is it effective? Obstetrics \& gynecology science. 2016; 59:24-31.

11. Bokhman JV, Chepick OF, Volkova AT, Vishnevsky AS. Can primary endometrial carcinoma stage I be cured without surgery and radiation therapy. Gynecologic oncology. 1985; 120:139-155.

12. Cade TJ, Quinn MA, Rome RM, Neesham D. Long-term outcomes after progestogen treatment for early endometrial cancer. The Australian \& New Zealand journal of obstetrics \& gynaecology. 2013; 53:566-570.

13. Cao DY, Yu M, Yang JX, Shen K, Huang HF, Cheng NH, Sun ZY, Deng CY, Yu Q, He FF. [Pregnant rate and pregnancy-relating factors of patients with early endometrial carcinoma and severe atypical hyperplasia of endometrium after fertility-preserving treatment by progestin]. [Article in Chinese]. Zhonghua fu chan ke za zhi. 2013; 48:519-522.

14. Chen M, Jin Y, Li Y, Bi Y, Shan Y, Pan L. Oncologic and reproductive outcomes after fertility-sparing management with oral progestin for women with complex endometrial hyperplasia and endometrial cancer. International journal of gynaecology and obstetrics. 2016; 132:34-38.

15. Dursun P, Erkanli S, Guzel AB, Gultekin M, Tarhan NC, Altundag O, Demirkiran F, Bese T, Yildirim Y, Bozdag G, Yarali H, Simsek T, Ozcelik B, et al. A Turkish Gynecologic Oncology Group study of fertility-sparing treatment for early-stage endometrial cancer. International journal of gynaecology and obstetrics. 2012; 119:270-273.

16. Duska LR, Garrett A, Rueda BR, Haas J, Chang Y, Fuller AF. Endometrial cancer in women 40 years old or younger. Gynecologic oncology. 2001; 83:388-393.

17. Eftekhar Z, Izadi-Mood N, Yarandi F, Shojaei H, Rezaei Z, Mohagheghi S. Efficacy of megestrol acetate (megace) in the treatment of patients with early endometrial adenocarcinoma: our experiences with 21 patients. International journal of gynecological cancer. 2009; 19:249-252.

18. Elizur SE, Beiner ME, Korach J, Weiser A, Ben-Baruch G, Dor J. Outcome of in vitro fertilization treatment in infertile women conservatively treated for endometrial adenocarcinoma. Fertility and sterility. 2007; 88:1562-1567.

19. Fujiwara H, Jobo T, Takei Y, Saga Y, Imai M, Arai T, Taneichi A, Machida S, Takahashi Y, Suzuki M. Fertilitysparing treatment using medroxyprogesterone acetate for endometrial carcinoma. Oncology letters. 2012; 3:1002-1006.

20. Gotlieb W. Outcome of fertility-sparing treatment with progestins in young patients with endometrial cancer. Obstetrics \& Gynecology. 2003; 102:718-725.

21. Hahn HS, Yoon SG, Hong JS, Hong SR, Park SJ, Lim JY, Kwon YS, Lee IH, Lim KT, Lee KH, Shim JU, Mok JE, Kim TJ. Conservative treatment with progestin and pregnancy outcomes in endometrial cancer. International journal of gynecological cancer. 2009; 19:1068-1073.

22. Han AR, Kwon YS, Kim DY, Kim JH, Kim YM, Kim YT, Nam JH. Pregnancy outcomes using assisted reproductive technology after fertility-preserving therapy in patients with endometrial adenocarcinoma or atypical complex hyperplasia. International journal of gynecological cancer. 2009; 19:147-151.

23. Ohyagi-Hara C, Sawada K, Aki I, Mabuchi S, Kobayashi E, Ueda Y, Yoshino K, Fujita M, Tsutsui T, Kimura T. Efficacies and pregnant outcomes of fertilitysparing treatment with medroxyprogesterone acetate for endometrioid adenocarcinoma and complex atypical hyperplasia: our experience and a review of the literature. Archives of gynecology and obstetrics. 2015; 291:151-157.

24. Jadoul P, Donnez J. Conservative treatment may be beneficial for young women with atypical endometrial hyperplasia or endometrial adenocarcinoma. Fertility and sterility. 2003; 80:1315-1324.

25. Kaku T, Yoshikawa H, Tsuda H, Sakamoto A, Fukunaga M, Kuwabara Y, Hataeg M, Kodama S, Kuzuya K, Sato S, Nishimura T, Hiura M, Nakano $H$, et al. Conservative therapy for adenocarcinoma and atypical endometrial hyperplasia of the endometrium in young women: central pathologic review and treatment outcome. Cancer letters. 2001; 167:39-48.

26. Kataoka H, Mori T, Yamamoto T, Sawada M, Kuroboshi H, Tatsumi H, Iwasaku K, Kitawaki J. Outcome of fertilitysparing treatment with medroxyprogesterone acetate for atypical hyperplasia and endometrial carcinoma in young Japanese women. European journal of gynaecological oncology. 2014; 35:11-15.

27. Kim YB, Holschneider CH, Ghosh K, Nieberg RK, Montz FJ. Progestin alone as primary treatment of endometrial carcinoma in premenopausal women. Report of seven cases and review of the literature. Cancer letters. 1997; 79:320-327.

28. Kim MK, Seong SJ, Kim YS, Song T, Kim ML, Yoon BS, Jun HS, Lee YH. Combined medroxyprogesterone acetate/ levonorgestrel-intrauterine system treatment in young women with early-stage endometrial cancer. American journal of obstetrics and gynecology. 2013; 209:358 e351-354.

29. Kim MK, Seong SJ, Kim JW, Jeon S, Choi HS, Lee IH, Lee JH, Ju W, Song ES, Park H, Ryu HS, Lee C, Kang SB. Management of Endometrial Hyperplasia With a Levonorgestrel-Releasing Intrauterine System: A Korean Gynecologic-Oncology Group Study. International journal of gynecological cancer. 2016; 26:711-715.

30. Koskas M, Azria E, Walker F, Luton D, Madelenat P, Yazbeck C. Progestin treatment of atypical hyperplasia and well-differentiated adenocarcinoma of the endometrium to preserve fertility. Anticancer research. 2012; 32:1037-1043.

31. Mao Y, Wan X, Chen Y, Lv W, Xie X. Outcomes of conservative therapy for young women with early endometrial adenocarcinoma. Fertility and sterility. 2010; 93:283-285.

32. De Marzi P, Bergamini A, Luchini S, Petrone M, Taccagni GL, Mangili G, Colombo G, Candiani M. Hysteroscopic Resection in Fertility-Sparing Surgery for Atypical Hyperplasia and Endometrial Cancer: Safety and Efficacy. Journal of minimally invasive gynecology. 2015; 22:1178-1182. 
33. Mentrikoski MJ, Shah AA, Hanley KZ, Atkins KA. Assessing endometrial hyperplasia and carcinoma treated with progestin therapy. American journal of clinical pathology. 2012; 138:524-534.

34. Minaguchi T, Nakagawa S, Takazawa Y, Nei T, Horie K, Fujiwara T, Osuga Y, Yasugi T, Kugu K, Yano T, Yoshikawa H, Taketani Y. Combined phospho-Akt and PTEN expressions associated with post-treatment hysterectomy after conservative progestin therapy in complex atypical hyperplasia and stage Ia, G1 adenocarcinoma of the endometrium. Cancer letters. 2007; 248:112-122.

35. Minig L, Franchi D, Boveri S, Casadio C, Bocciolone L, Sideri M. Progestin intrauterine device and GnRH analogue for uterus-sparing treatment of endometrial precancers and well-differentiated early endometrial carcinoma in young women. Annals of oncology. 2011; 22:643-649.

36. Niwa K, Tagami K, Lian Z, Onogi K, Mori H, Tamaya T. Outcome of fertility-preserving treatment in young women with endometrial carcinomas. BJOG. 2005; 112:317-320.

37. Nomura H, Sugiyama Y, Tanigawa T, Matoda M, Kanao H, Kondo E, Takeshima N. Long-term outcomes of fertilitysparing treatment of atypical polypoid adenomyoma with medroxyprogesterone acetate. Archives of gynecology and obstetrics. 2016; 293:177-181.

38. Ota $T$, Yoshida M, Kimura M, Kinoshita K. Clinicopathologic study of uterine endometrial carcinoma in young women aged 40 years and younger. International journal of gynecological cancer. 2005; 15:657-662.

39. Park H, Seok JM, Yoon BS, Seong SJ, Kim JY, Shim JY, Park CT. Effectiveness of high-dose progestin and longterm outcomes in young women with early-stage, welldifferentiated endometrioid adenocarcinoma of uterine endometrium. Archives of gynecology and obstetrics. 2012; 285:473-478.

40. Park JY, Seong SJ, Kim TJ, Kim JW, Kim SM, Bae DS, Nam JH. Pregnancy Outcomes After Fertility-Sparing Management in Young Women With Early Endometrial Cancer. Obstetrics \& Gynecology. 2013; 121:136-142.

41. Penner KR, Dorigo O, Aoyama C, Ostrzega N, Balzer BL, Rao J, Walsh CS, Cass I, Holschneider CH. Predictors of resolution of complex atypical hyperplasia or grade 1 endometrial adenocarcinoma in premenopausal women treated with progestin therapy. Gynecologic oncology. 2012; 124:542-548.

42. Perri T, Korach J, Gotlieb WH, Beiner M, Meirow D, Friedman E, Ferenczy A, Ben-Baruch G. Prolonged conservative treatment of endometrial cancer patients: more than 1 pregnancy can be achieved. International journal of gynecological cancer. 2011; 21:72-78.

43. Pronin SM, Novikova OV, Andreeva JY, Novikova EG. Fertility-Sparing Treatment of Early Endometrial Cancer and Complex Atypical Hyperplasia in Young Women of Childbearing Potential. International journal of gynecological cancer. 2015; 25:1010-1014.
44. Randall TC, Kurman RJ. Progestin treatment of atypical hyperplasia and well-differentiated carcinoma of the endometrium in women under age 40. Obstetrics and gynecology. 1997; 90:434-440.

45. Ricciardi E, Maniglio P, Frega A, Marci R, Caserta D, Moscarini M. Fertility-sparing treatment of endometrial cancer precursors among young women: a reproductive point of view. European review for medical and pharmacological sciences. 2012; 16:1934-1937.

46. Shan BE, Ren YL, Sun JM, Tu XY, Jiang ZX, Ju XZ, Zang RY, Wang HY. A prospective study of fertility-sparing treatment with megestrol acetate following hysteroscopic curettage for well-differentiated endometrioid carcinoma and atypical hyperplasia in young women. Archives of gynecology and obstetrics. 2013; 288:1115-1123.

47. Shan W, Wang C, Zhang Z, Gu C, Ning C, Luo X, Zhou Q, Chen X. Conservative therapy with metformin plus megestrol acetate for endometrial atypical hyperplasia. Journal of gynecologic oncology. 2014; 25:214-220.

48. Shirali E, Yarandi F, Eftekhar Z, Shojaei H, Khazaeipour Z. Pregnancy outcome in patients with stage 1a endometrial adenocarcinoma, who conservatively treated with megestrol acetate. Archives of gynecology and obstetrics. 2012; 285:791-795.

49. Jafari Shobeiri M, Mostafa Gharabaghi P, Esmaeili H, Ouladsahebmadarek E, Mehrzad-Sadagiani M. Fertility sparing treatment in young patients with early endometrial adenocarcinoma. Pakistan Journal of Medical Sciences. $2013 ; 29$.

50. Simpson AN, Feigenberg T, Clarke BA, Gien LT, Ismiil N, Laframboise S, Massey C, Ferguson SE. Fertility sparing treatment of complex atypical hyperplasia and low grade endometrial cancer using oral progestin. Gynecologic oncology. 2014; 133:229-233.

51. Ushijima K, Yahata H, Yoshikawa H, Konishi I, Yasugi T, Saito T, Nakanishi T, Sasaki H, Saji F, Iwasaka T, Hatae M, Kodama S, Saito T, et al. Multicenter phase II study of fertility-sparing treatment with medroxyprogesterone acetate for endometrial carcinoma and atypical hyperplasia in young women. Journal of clinical oncology. 2007; 25:2798-2803.

52. Wang HY, Shen L, Sun Z. [Endometrial adenocarcinoma in women 40 years old or younger by treatment with progestins: report of 6 cases and review of the literatures]. [Article in Chinese]. Zhonghua fu chan ke za zhi. 2006; 41:237-241.

53. Wang CB, Wang CJ, Huang HJ, Hsueh S, Chou HH, Soong YK, Lai CH. Fertility-preserving treatment in young patients with endometrial adenocarcinoma. Cancer. 2002; 94:2192-2198.

54. Wheeler DT, Bristow RE, Kurman RJ. Histologic alterations in endometrial hyperplasia and well-differentiated carcinoma treated with progestins. The American journal of surgical pathology. 2007; 31:988-998. 
55. Yahata T, Fujita K, Aoki Y, Tanaka K. Long-term conservative therapy for endometrial adenocarcinoma in young women. Human reproduction. 2006; 21:1070-1075.

56. Yamazawa K, Hirai M, Fujito A, Nishi H, Terauchi F, Ishikura H, Shozu M, Isaka K. Fertility-preserving treatment with progestin, and pathological criteria to predict responses, in young women with endometrial cancer. Human reproduction. 2007; 22:1953-1958.

57. Yang $\mathrm{YC}, \mathrm{Wu} \mathrm{CC}$, Chen $\mathrm{CP}$, Chang CL, Wang KL. Reevaluating the safety of fertility-sparing hormonal therapy for early endometrial cancer. Gynecologic oncology. 2005; 99:287-293.

58. Yu M, Shen K, Yang JX, Huang HF, Wu M, Pan LY, Lang JH, Lian LJ. [Outcome analysis of conservative treatment of well-differentiated endometrial adenocarcinoma and severe atypical hyperplasia in young women]. [Article in Chinese]. Zhonghua fu chan ke za zhi. 2006; 41:242-245.

59. Zhou R, Yang Y, Lu Q, Wang J, Miao Y, Wang S, Wang Z, Zhao C, Wei L. Prognostic factors of oncological and reproductive outcomes in fertility-sparing treatment of complex atypical hyperplasia and low-grade endometrial cancer using oral progestin in Chinese patients. Gynecologic oncology. 2015; 139:424-428.

60. Pashov AI, Tskhay VB, Ionouchene SV. The combined GnRH-agonist and intrauterine levonorgestrel-releasing system treatment of complicated atypical hyperplasia and endometrial cancer: a pilot study. Gynecological endocrinology. 2012; 28:559-561.

61. Falcone F, Laurelli G, Losito S, Di Napoli M, Granata V, Greggi S. Fertility preserving treatment with hysteroscopic resection followed by progestin therapy in young women with early endometrial cancer. Journal of gynecologic oncology. 2017; 28:e2.

62. Wang Q, Guo Q, Gao S, Xie F, Du M, Dong J, Sui L, Xie K. Fertility-conservation combined therapy with hysteroscopic resection and oral progesterone for local early stage endometrial carcinoma in young women. International journal of clinical and experimental medicine. 2015; 8:13804-13810.

63. Kelley RM, Baker WH. Progestational agents in the treatment of carcinoma of the endometrium. N Engl J Med. 1961; 264:216-222.

64. Yu M, Shen K, Yang JX, Huang HF, Wu M, Pan LY, Lang JH, Lian LJ. [Outcome analysis of conservative treatment of well-differ-entiated endometrial adenocarcinoma and severe atypical hyperplasia in young women]. [Article in Chinese]. Chung Hua Fu Chan Ko Tsa Chih. 2006; 41:242-245.

65. Erkanli S, Ayhan A. Fertility-Sparing Therapy in Young Women With Endometrial Cancer. International Journal of Gynecological Cancer. 2010; 20:1170-1187.

66. Baker J, Obermair A, Gebski V, Janda M. Efficacy of oral or intrauterine device-delivered progestin in patients with complex endometrial hyperplasia with atypia or early endometrial adenocarcinoma: a meta-analysis and systematic review of the literature. Gynecologic oncology. 2012; 125:263-270.
67. Ørbo A, Vereide AB, Arnes M, Pettersen I, Straume B. Levonorgestrel-impregnated intrauterine device as treatment for endometrial hyperplasia: a national multicentre randomised trial. BJOG. 2014; 121:477-486.

68. Kim MK, Seong SJ, Song T, Kim ML, Yoon BS, Jun HS, Lee GH, Lee YH. Comparison of dilatation \& curettage and endometrial aspiration biopsy accuracy in patients treated with high-dose oral progestin plus levonorgestrel intrauterine system for early-stage endometrial cancer. Gynecologic oncology. 2013; 130:470-473.

69. Dolapcioglu K, Boz A, Baloglu A. The efficacy of intrauterine versus oral progestin for the treatment of endometrial hyperplasia. A prospective randomized comparative study. Clin Exp Obstet Gynecol. 2013; 40:122-126.

70. Karimi-Zarchi M, Dehghani-Firoozabadi R, Tabatabaie A, Dehghani-Firoozabadi Z, Teimoori S, Chiti Z, MiratashiYazdi A, Dehghani A. A comparison of the effect of levonorgestrel IUD with oral medroxyprogesterone acetate on abnormal uterine bleeding with simple endometrial hyperplasia and fertility preservation. Clin Exp Obstet Gynecol. 2013; 40:421-424.

71. Laurelli G, Di Vagno G, Scaffa C, Losito S, Del Giudice M, Greggi S. Conservative treatment of early endometrial cancer: Preliminary results of a pilot study. Gynecologic oncology. 2011; 120:43-46.

72. Laurelli G, Falcone F, Gallo MS, Scala F, Losito S, Granata V, Cascella M, Greggi S. Long-Term Oncologic and Reproductive Outcomes in Young Women With Early Endometrial Cancer Conservatively Treated: A Prospective Study and Literature Update. International journal of gynecological cancer. 2016; 26:1650-1657.

73. Gonthier C, Madelenat P, Walker F, Luton D, Koskas M. Hysteroscopic resection in the management of early-stage endometrial cancer: report of 2 cases and review of the literature. Journal of minimally invasive gynecology. 2015; 22:511-512.

74. Parlakgumus HA, Kilicdag EB, Simsek E, Haydardedeoglu B, Cok T, Aytac PC, Bagis T, Erkanli S. Fertility outcomes of patients with early stage endometrial carcinoma. The journal of obstetrics and gynaecology research. 2014; 40:102-108.

75. Lo KW, Cheung TH, Yim SF, Chung TK. Hysteroscopic dissemination of endometrial carcinoma using carbon dioxide and normal saline: a retrospective study. Gynecologic oncology. 2002; 84:394-398.

76. Gonthier C, Walker F, Luton D, Yazbeck C, Madelenat P, Koskas M. Impact of obesity on the results of fertility-sparing management for atypical hyperplasia and grade 1 endometrial cancer. Gynecologic oncology. 2014; 133:33-37.

77. Takeshima N, Hirai Y, Yano K, Tanaka N, Yamauchi K, Hasumi K. Ovarian metastasis in endometrial carcinoma. Gynecologic oncology. 1998; 70:183-187.

78. Signorelli M, Caspani G, Bonazzi C, Chiappa V, Perego P, Mangioni C. Fertility-sparing treatment in young women with endometrial cancer or atypical complex hyperplasia: a prospective single-institution experience of 21 cases. BJOG. 2009; 116:114-118. 
79. Slim K, Nini E, Forestier D, Kwiatkowski F, Panis Y, Chipponi J. Methodological index for non-randomized studies (minors): development and validation of a new instrument. ANZ J Surg. 2003; 73:712-716.

80. DerSimonian R, Laird N. Meta-analysis in clinical trials revisited. Contemporary clinical trials. 2015; 45:139-145.

81. Lewis S, Clarke M. Forest plots trying to see the wood and the trees. BMJ. 2001; 322:1479-1480.
82. Luo ML, Tan HZ, Zhou Q, Wang SY, Cai C, Guo YW, Shen L. Realizing the Meta-Analysis of Single Rate in R Software. The Journal of Evidence-Based Medicine. 2013; 13:181-184. 